\title{
The safety of intracytoplasmic sperm injection in men with hepatitis $B$
}

Zhong Zheng ${ }^{1}$, Xiaoming Zhao ${ }^{2}$, Yan Hong ${ }^{1}$, Bing X $\mathrm{X}^{1}$, Jing Tong ${ }^{1}$, Lan Xia ${ }^{1}$

\author{
${ }^{1}$ Department of Reproduction, Ren Ji Hospital, School of Medicine, Shanghai Jiao Tong \\ University, Shanghai, China \\ ${ }^{2}$ Shanghai Key Laboratory for Assisted Reproduction and Reproductive Genetics, \\ Center for Reproductive Medicine, Renji Hospital, Shanghai Jiaotong University, \\ Shanghai, China
}

Submitted: 2 May 2014

Accepted: 15 August 2014

Arch Med Sci 2016; 12, 3: 587-591

DOI: 10.5114/aoms.2016.59933

Copyright $\odot 2016$ Termedia \& Banach

\section{Abstract}

Introduction: In this study, we aimed to evaluate the safety of using different sources of sperm when male partners were infected with hepatitis $B$ virus (HBV).

Material and methods: A total of 338 couples receiving their first intracytoplasmic sperm injection (ICSI) cycle at the Department of Reproduction, Ren Ji Hospital, between 2007 and 2012 were enrolled if the female partner tested negative for HBV DNA, HBsAg, $\mathrm{HBeAg}, \mathrm{HBeAb}$ and $\mathrm{HBCAb}$. Couples were divided into HBV active infection (group B), convalescent infection (group C) and controls (group A). Subgroups were divided by source of sperm: ejaculated sperm and testicular sperm aspiration/percutaneous epididymal sperm aspiration (TESA/PESA) sperm.

Results: When using ejaculated sperm for ICSI, two pronuclear (2PN) fertilization rate, implantation rate, clinical pregnant rate, early miscarriage rate and live birth rate showed no significant difference between the three groups. However, in the three TESA/PESA groups, the early miscarriage rate was highest in men with active HBV infection (B2) $(23.1 \%, p=0.035)$. The $2 \mathrm{PN}$ fertilization rate and CPR were also lower in the active infection group $(76.7 \%, 26.3 \%)$ than the convalescent infection $(82.9 \%, 36.2 \%)$ and control group $(78.2 \%, 50 \%)$, but the difference was not statistically significant. No malformed infant was found in any of these groups.

Conclusions: When men have an active HBV infection, using TESA/PESA sperm may cause lower fertilization, a high miscarriage rate and a lower live birth rate, which indicates that HBV active infection may cause adverse effects on ICSI reproductive performance when using testicular or epididymal aspirated sperm.

Key words: hepatitis B virus, intracytoplasmic sperm injection, male infertility.

\section{Introduction}

Hepatitis B virus (HBV) infection is a serious public health problem in China. Although a minority of individuals infected by HBV will develop a persistent infection [1], a total of roughly 200 million Chinese people suffer from chronic hepatitis B infection, about $8 \%$ of the country's total population [2].

\author{
Corresponding author: \\ Xiaoming Zhao PhD \\ Renji Hospital \\ Shanghai Jiaotong University \\ No. 845 Lingshan Road \\ Pudong \\ 200135 Shanghai, China \\ Phone: +86 13916308054 \\ E-mail: zhao_xiao_ming@ \\ 126.com
}


As the number of couples seeking in vitro fertilization-embryo transfer (IVF-ET) increases year on year, the impact on IVF/intracytoplasmic sperm injection (ICSI) outcome is of concern if one or both members of a couple is affected by HBV. Although HBV concentration can be decreased during ex vivo semen processing, HBV integrated into host cells cannot be eliminated [3]. Hepatitis $B$ virus is confirmed to integrate into the chromosome of sperm, which causes reduced motility, increased apoptosis and necrosis [4-6] and mediates a mutagenic effect on sperm chromosomes, inducing chromosome aberrations [7] and resulting in reduced male fertility.

One study in 2004 found that men who tested positive for serum HBV DNA were associated with low implantation and pregnancy rates but a similar fertilization rate in IVF cycles [4]. However, it was also reported that couples undergoing IVF-ET in which the male tested positive for HBV DNA had an increased pregnancy rate [8].

The latest results showed that HBsAg-seropositive men had similar IVF outcomes to the control group, but decreased rates of implantation and clinical pregnancy were found in ICSI cycles.

Intracytoplasmic sperm injection has two sources of sperm: ejaculated sperm and TESA/PESA sperm. Moreover, HBV infection has two stages: the active and convalescent stage, in which virus concentration in peripheral blood is different. These two factors may cause variable results of ICSI. So our retrospective cohort study attempts to evaluate the impact on the outcome of ICSI when men are in two HBV infection stages diagnosed by five HBV markers and discuss their feasibility of ICSI.

\section{Material and methods}

\section{Subjects}

All couples receiving their first ICSI cycles in the Department of Reproduction, Ren Ji Hospital, School of Medicine, Shanghai Jiao Tong University, Shanghai, China, between 2007 and 2012 were enrolled in a retrospective study. All patients with chromosomal abnormalities or acute or chronic infectious diseases aside from HBV were excluded, as were any couples in which the female partner tested positive for serum $\mathrm{HBsAg}, \mathrm{HBeAg}, \mathrm{HBeAb}$ or $\mathrm{HBCAb}$, determined with diagnostic ELISA kits (Roche, USA), or HBV-DNA, determined by FQ-PCR with a cut-off of $10^{3}$ copies $/ \mathrm{ml}$.

Patients were divided into two groups according to the male partner's HBV serostatus, which was assessed within the year preceding IVF commencement: group B (active infection) - HBV DNA seropositive; and group C (convalescent infection) - HBsAg, HBeAb and HBcAb positive and HBV DNA negative. We matched the female age, date of ICSI, basal FSH, ICSI protocol, and number of embryos transferred and found 121 couples as the control group (group A): male negative for $\mathrm{HBsAg}$, $\mathrm{HBeAg}, \mathrm{HBeAb}$ and HBcAb and HBV-DNA. Then according to different sources of sperm, we divided these three groups into the ejaculated group (A1, B1, C1) and TESA/PESA sperm (A2, B2, C2)

\section{Controlled ovarian hyperstimulation protocol}

Ovulation was induced in all patients by either the long or short protocol. The long protocol following the regular long protocol [9] involved pituitary down-regulation from the $7^{\text {th }}$ day after ovulation by subcutaneous injection of $0.05 \mathrm{mg}$ triptorelin (Ferring $\mathrm{GmbH}$, Kiel, Germany), and measurement of serum luteinizing hormone $(\mathrm{LH})$ and estradiol $\left(E_{2}\right)$ levels and ultrasound on the $3^{\text {rd }}$ day of the next menstrual cycle. When LH levels $\leq 5 \mathrm{IU} / \mathrm{l}, \mathrm{E}_{2}$ levels fell below $50 \mathrm{pg} / \mathrm{ml}$ and no follicle greater than $10 \mathrm{~mm}$ in diameter was observed by ultrasound, we began injecting rFSH (Gonal F, Merk Serono Switzerland). On the second or third day of the next menstrual cycle we injected $0.1 \mathrm{mg}$ triptorelin and 150-300 IU rFSH. The ovarian response was monitored by ultrasound and serum $E_{2}$ concentrations. When at least two dominant follicles reached $18 \mathrm{~mm}$ in diameter, an ovulatory dose of 5000-10000 IU hCG (Livzon Bio-chemical Pharmaceutical Co., Zhuhai, China) was given and oocyte retrieval was performed within 34-36 h. Intracytoplasmic sperm injection was carried out four to $6 \mathrm{~h}$ later [10]. One to three embryos were transferred 2 to 3 days after retrieval. All transferred embryos were composed of four to five cells on day two, and seven or more cells on day three. The blastomeres were of equal size and less than $20 \%$ fragmentation and no multinucleation was detected [11]. Luteal support was provided from the $2^{\text {nd }}$ day of retrieval by IM (60 mg/day) or vaginal (90 mg/day) progesterone (Crinone Merk-Serono, Switzerland) combined with $10 \mathrm{mg}$ of oral dydrogesterone (Abbott, Holland).

\section{Sperm acquisition}

Sperm was collected on the day the wife retrieved the oocytes. There were two sources:

- Fresh ejaculated sperm was obtained on the oocyte retrieval day when men were oligozoospermic or asthenozoospermic.

- Percutaneous epididymal sperm aspiration (PESA) and testicular sperm aspiration (TESA) sperm was executed when men were azoospermic on the day of oocyte retrieval. Testicular sperm aspiration was performed in patients with non-obstructive azoospermia which was previously diagnosed. 


\section{Outcomes measured}

Pregnancy was detected by urine or serum test 14 days after embryo transfer. If positive, a vaginal ultrasound scan of the pelvis was performed 2 weeks later to assess the implantation site, the number and viability of gestation. Childbirth was confirmed by follow-up mail or telephone call. Preterm birth was defined as gestational age $\geq 28$ weeks and $<37$ weeks.

\section{Statistical analysis}

Statistical analyses were performed using SPSS, version 18.0 (SPSS Inc, Chicago, IL, USA). One-way ANOVA was applied for continuous variables and all categorical data were analyzed using $\chi^{2}$ tests. $P$-value $<0.05$ was considered statistically significant.

\section{Results}

Between 2007 and 2012, our reproductive department carried out a total of 7978 IVF/ICSI cycles from which 338 couples were enrolled in this study. Group A included 121 couples, group B 92 and group $C 125$. There were no significant differences in female or male age, basal FSH, dose of $\mathrm{Gn}$, serum $\mathrm{E}_{2}$, endometrium thickness on the day of hCG or number of embryos transferred (Table I).

Comparison of ICSI outcome using different sources of sperm in two HBV infection groups

We compared among the 3 ejaculated groups and 3 TESA/PESA groups. In the 3 ejaculated groups, 2PN fertilization rate, clinical pregnant rate, early miscarriage rate and live birth rate showed no significant differences. However, we observed that the $2 \mathrm{PN}$ fertilization rate was lower in the active infection group (B2) using TESA/PESA sperm (76.7\%, $p=0.06)$ compared to the convalescent infection group (C2) or control group (A2). Meanwhile, the early miscarriage rate in $\mathrm{B} 2$ was $23.1 \%$, the highest among $A 2, B 2$ and $C 2$ groups, $p=0.035$. Consistently, CPR was lower in B2 than A2 and C2 (27.3\%, $50 \%, 36.2 \%$, respectively, $p=0.12$ ).

Neonatal birth weight did not have statistical significance and there was no malformed infants in the active infected group (B1 and B2) and convalescent group ( $\mathrm{C} 1$ and $\mathrm{C} 2$ ). Table II shows the mean weight \pm SD of neonatal birth weight.

\section{Discussion}

Hepatitis B virus is a double-stranded DNA virus belonging to the Hepadnaviridae family which is confirmed to penetrate the blood-testis barrier, enter the male germ line and integrate into their genome and hence increase the instability of sperm chromosomes [4]. Moretti et al. suggested that HBV infection could create extensive hereditary effects by altering genetic constituents and/ or inducing chromosome aberrations, as well as the possibility of the vertical transmission of HBV via the germ line to the next generation [4].

Huang et al. also found that sperm of the subjects with HBV infection appeared to be able to penetrate into zona-free hamster oocytes and to develop to the first-cleavage metaphase [12, 13]. Among the analyzable metaphase spreads, chromosome aberrations observed included numerical anomaly (aneuploidy), gap, ring chromosome, tri-

Table I. Clinical characteristics of enrolled patients

\begin{tabular}{|c|c|c|c|c|c|c|c|}
\hline \multirow[t]{2}{*}{ Parameter } & \multicolumn{2}{|c|}{$\begin{array}{l}\text { Control (A) } \\
(N=121)\end{array}$} & \multicolumn{2}{|c|}{$\begin{array}{l}\text { Active infection (B) } \\
\qquad(N=92)\end{array}$} & \multicolumn{2}{|c|}{$\begin{array}{l}\text { Convalescent infection } \\
\text { (C) }(N=125)\end{array}$} & \multirow[t]{2}{*}{$P$-value } \\
\hline & $\begin{array}{c}\text { Ejaculated } \\
\text { (A1) } \\
N=77\end{array}$ & $\begin{array}{c}\text { TESA/ } \\
\text { PESA (A2) } \\
N=44\end{array}$ & $\begin{array}{c}\text { Ejaculated } \\
\text { (B1) } \\
N=59\end{array}$ & $\begin{array}{c}\text { TESA/ } \\
\text { PESA (B2) } \\
N=33\end{array}$ & $\begin{array}{c}\text { Ejaculated } \\
\text { (C1) } \\
N=78\end{array}$ & $\begin{array}{c}\text { TESA/ } \\
\text { PESA (C2) } \\
N=47\end{array}$ & \\
\hline Female age [years] & $30.6 \pm 3.8$ & $29.6 \pm 3.0$ & $30.7 \pm 4.1$ & $28.9 \pm 5.1$ & $31.1 \pm 4.1$ & $30.3 \pm 4.7$ & 0.12 \\
\hline Male age [years] & $32.7 \pm 5.1$ & $31.8 \pm 4.7$ & $32.4 \pm 5.2$ & $31.6 \pm 5.5$ & $32.9 \pm 5.1$ & $33.0 \pm 5.3$ & 0.71 \\
\hline Basal FSH [IU/I] & $6.7 \pm 1.8$ & $7.1 \pm 1.9$ & $7.4 \pm 2.2$ & $6.5 \pm 1.5$ & $7.0 \pm 2.4$ & $7.1 \pm 2.3$ & 0.44 \\
\hline Dosage of Gn [IU] & $\begin{array}{l}1491.8 \\
\pm 315.5\end{array}$ & $\begin{array}{l}1532.7 \\
\pm 377.6\end{array}$ & $\begin{array}{l}1479.4 \\
\pm 370.6\end{array}$ & $\begin{array}{l}1532.1 \\
\pm 533.1\end{array}$ & $\begin{array}{l}1544.8 \\
\pm 445.9\end{array}$ & $\begin{array}{l}1434.0 \\
\pm 472.5\end{array}$ & 0.74 \\
\hline $\begin{array}{l}\text { E2 level on HCG day } \\
{[\mathrm{pg} / \mathrm{ml}]}\end{array}$ & $\begin{array}{c}3486.9 \\
\pm 1676.9\end{array}$ & $\begin{array}{c}3644.5 \\
\pm 1748.6\end{array}$ & $\begin{array}{c}3486.8 \\
\pm 1809.2\end{array}$ & $\begin{array}{c}3665.3 \\
\pm 1734.6\end{array}$ & $\begin{array}{c}3583.5 \\
\pm 1969.4\end{array}$ & $\begin{array}{c}3470.1 \\
\pm 1937.3\end{array}$ & 0.99 \\
\hline $\begin{array}{l}\text { Thickness of } \\
\text { endometrium on HCG } \\
\text { day }[\mathrm{mm}]\end{array}$ & $9.9 \pm 1.6$ & $9.9 \pm 1.8$ & $10.0 \pm 1.8$ & $10.0 \pm 2.3$ & $10.2 \pm 1.9$ & $10.0 \pm 1.5$ & 0.94 \\
\hline Retrieved oocytes & $12.8 \pm 6.9$ & $11.5 \pm 5.0$ & $11.7 \pm 7.5$ & $13.7 \pm 7.2$ & $12.4 \pm 6.7$ & $11.7 \pm 5.3$ & 0.63 \\
\hline Embryo transferred & $2.1 \pm 0.2$ & $2.0 \pm 0.2$ & $2.1 \pm 0.4$ & $2.1 \pm 0.3$ & $2.1 \pm 0.4$ & $2.0 \pm 0.4$ & 0.90 \\
\hline
\end{tabular}




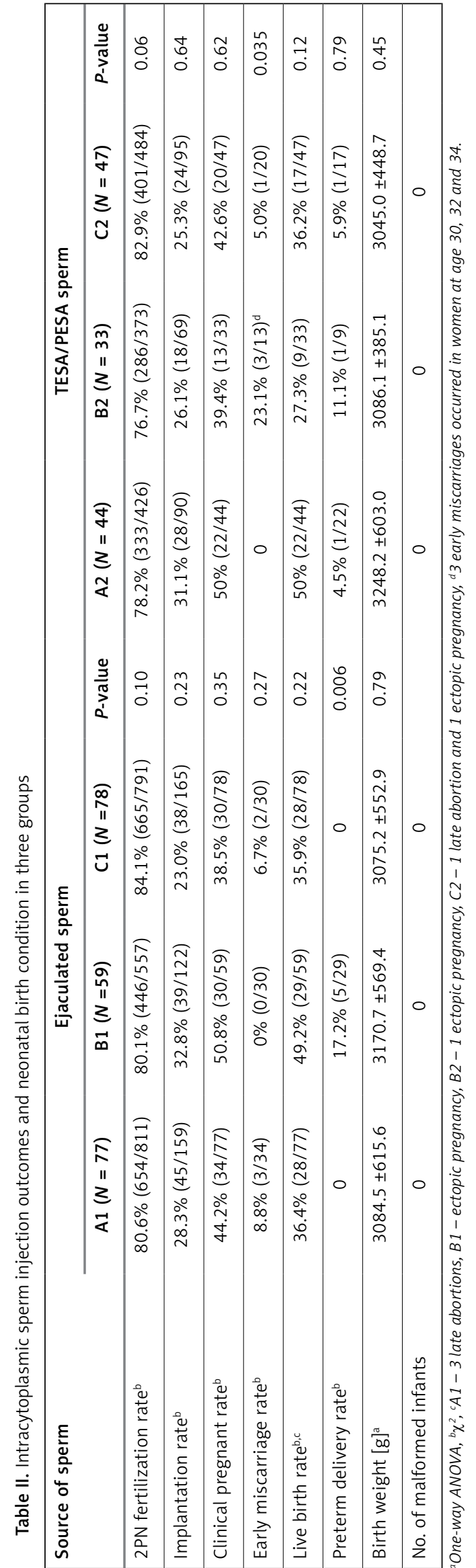

radial, dicentric chromosome, pulverization, acentric fragment and deletion. They observed that 33 out of $233(14.8 \%)$ analyzable sperm metaphase spreads in the hepatitis group contained chromosome aberrations. This incidence rate was significantly higher than that in the control group (4.3\%, $p<0.005$ ) [12]. Furthermore, they confirmed that HBV DNA was able to integrate into a human sperm chromosome by the discovery of $5 \mathrm{HBV}$ DNA signals on different sperm chromosomes by FISH in a serum HBV-DNA positive person.

The overall influence of HBV-infected men on IVF outcome is controversial $[6,8]$ and not discussed in this paper. However, Zhou et al. found ICSI results to be adversely affected by a HBV-infected male partner [6]. In their study, the fertility rate, good embryo rate, implantation rate and PR (70.9\%, 57.6\%, $18.3 \%$ and $31.2 \%$, respectively) in the seropositive HBsAg group were statistically significantly lower than in controls $(74.0 \%, 60.4 \%$, $24.2 \%, 39.3 \%)$.

Our results showed that HBV actively infected men using PESA/TESA for ICSI had a lower 2PN fertilization rate, live birth rate and high early miscarriage rate compared to the convalescent infection and control group. There was no difference in ICSI outcome between the convalescent and control group.

Some research has shown that the HBV infection rate of human sperm was much lower than that of liver cells, leading to a very low rate of male germ cell or embryo infection [2, 11], especially in the convalescent infection group. In this course of infection, HBV replication is in a stationary state and its body fluid concentration is lower, even to zero. When sperm are thoroughly washed, the density of HBV virus is also dramatically reduced. Qian et al. found a lower number of serum HBV DNA copies in sperm than in serum in $2 \mathrm{HBV}$ carriers [2]. Also, these people had been in a convalescent stage for more than 1 year, which exceed the spermatogenic cycle. These studies may explain why no adverse effect was observed in the HBV convalescent infection group.

Since there are different serum HBV concentrations in active and convalescent HBV infection stage, we speculate that during the course of percutaneous epididymal and testicular aspiration, a high concentration of virus will be passed from blood into extracts. This may raise the opportunity for virus contacting with sperm and integrating into sperm. Also sperm may be introduced into oocytes when performing ICSI. The integrations of viral DNA into sperm chromosomes with multisite and nonspecific features can further increase the instability of sperm chromosomes. Even if the zygote could develop to cleavage metaphase, the ability of embryo development would be impaired and cause a high miscarriage rate, which implies 
that HBV infection may affect the capacity for embryo development.

Miscarriage rates might be unaffected when sperm are collected by ejaculation due to different processing methods. In this study, density gradient centrifugation was used (different from the simple centrifugation used in TESA and PESA), which washed the semen more thoroughly. Moreover, the integration rate is low in ejaculated sperm (Huang et al. found that HBV DNA was only detected in one out of 9 men with chronic hepatitis B [12]).

In conclusion, the male partner with convalescent HBV infection did not appear to influence the outcome of ICSI. This should be noted when the husband in the active infection stage is undergoing ICSI using TESA/PESA sperm. For these patients we suggest that anti-virus is necessary before ICSI cycles. Studies of larger samples should be required for this group of infertile couples. Although our study followed up neonatal birth condition, it also remains unknown whether exogenous HBV gene fragments could have a long-term impact on human gene variation, which needs further exploration.

\section{Acknowledgments}

This project was supported by the National Natural Science Foundation of China (Grant No. 81370687).

\section{Conflict of interest}

The authors declare no conflict of interest.

\section{References}

1. Lok AS, McMahon BJ. Chronic hepatitis B. Hepatology 2007; 45: 507-39.

2. Qian WP, Tan YQ, Chen Y, et al. Rapid quantification of semen hepatitis B virus DNA by real-time polymerase chain reaction. World J Gastroenterol 2005; 11: 5385-9.

3. Garrido N, Meseguer M, Remohi J, Simon C, Pellicer A. Semen characteristics in human immunodeficiency virus (HIV)- and hepatitis C (HCV)-seropositive males: predictors of the success of viral removal after sperm washing. Hum Reprod 2005; 20: 1028-34.

4. Moretti E, Federico MG, Giannerini V, Collodel G. Sperm ultrastructure and meiotic segregation in a group of patients with chronic hepatitis B and C. Andrologia 2008; 40: 286-91.

5. Pirwany IR, Phillips S, Kelly S, Buckett W, Tan SL. Reproductive performance of couples discordant for hepatitis B and C following IVF treatment. J Assist Reprod Genet 2004; 21: 157-61.

6. Zhou XP, Hu XL, Zhu YM, et al. Comparison of semen quality and outcome of assisted reproductive techniques in Chinese men with and without hepatitis B. Asian J Androl 2011; 13: 465-9.

7. Zhou XL, Sun PN, Huang TH, et al. Effects of hepatitis B virus $\mathrm{S}$ protein on human sperm function. Hum Reprod 2009; 24: 1575-83.
8. Lam PM, Suen SH, Lao TT, et al. Hepatitis B infection and outcomes of in vitro fertilization and embryo transfer treatment. Fertil Steril 2010; 93: 480-5.

9. Moini A, Zadeh Modarress S, Amirchaqhmaghi E, et al. The effect of adding oral oestradiol to progesterone as luteal phase support in ART cycles - a randomized controlled study. Arch Med Sci 2011; 7: 112-6.

10. Esteves SC, Miyaoka R, Agarwal A. Sperm retrieval techniques for assisted reproduction. Int Braz J Urol 2011; 37: 570-83.

11. Gao MZ, Zhao XM, Lin Y, Sun ZG, Zhang HQ. Effects of EG-VEGF, VEGF and TGF-beta1 on pregnancy outcome in patients undergoing IVF-ET treatment. J Assist Reprod Genet 2012; 29: 1091-6.

12. Huang JM, Huang TH, Qiu HY, et al. Effects of hepatitis $B$ virus infection on human sperm chromosome. World J Gastroenterol 2003; 9: 736-40.

13. Huang JM, Huang TH, Qiu HY, et al. Studies on the integration of hepatitis B virus DNA sequence in human sperm chromosomes. Asian J Androl 2002; 4: 209-12. 